Silvia Izquierdo Todorović ${ }^{1}$ Universidad de Belgrado Facultad de Filología
UDK: 378.6:[821.134.4(7/8)+811.134.4(7/8)(497.11)

https://doi.org/10.18485/imp.2017.ch.18

\title{
LA CULTURA HISPANOAMERICANA EN EL DEPARTAMENTO DE LENGUA ESPAÑOLA Y LITERATURAS HISPÁNICAS. DESDE UNA PERSPECTIVA PERSONAL
}

En este trabajo presentaremos el lugar primordial y de gran trascendencia que desempeña el Departamento de Lengua Española y Literaturas Hispánicas de la Cátedra de Estudios Ibéricos de la Facultad de Filología de la Universidad de Belgrado, en el estudio de la cultura hispanoamericana, no sólo en Serbia, sino también, en los Balcanes. Se analizará en forma breve la recepción de la cultura hispanoamericana en Serbia, tema que resulta insoslayable en cualquier estudio haciendo hincapié, sobre todo en el campo de las traducciones de obras literarias del español al serbio y viceversa, donde los hispanistas egresados del Departamento ocupan un papel relevante.

Desde su fundación el Departamento de Lengua Española y Literaturas Hispánicas, junto a los estudios de la lengua, la literatura y cultura españolas; la literatura y la cultura hispanoamericanas han sido abordadas desde un punto de vista científico, estructurado, metodológico y multidisciplinar. Cuando se trata de la cultura hispanoamericana se ha empezando con las culturas y civilizaciones ancestrales y su perduración en el tiempo, cuya proyección es perceptible como sincretismo cultural y materia constante de estudios científicos. También se ha tratado el fenómeno de la transculturación, de gran trascendencia para conocer y comprender la identidad hispanoamericana. La transculturación o fusión biológica y cultural de los pueblos de España y las grandes culturas vernáculas de tiempos inmemoriales ha dado como resultado un mestizaje de gran repercusión en todas las áreas de la cultura hispanoamericana, que se ha visto enriquecida con nuevas inmigraciones y por ende, el nacimiento de una sociedad multiétnica y multicultural. Se ha sugerido, además, el estudio de la ciencia americanista y la elaboración de un Diccionario de americanismos.

Palabras claves: Departamento de Lengua Española y Literaturas Hispánicas. Cultura hispanoamericana. Sincretismo de culturas. Mestizaje. Identidad hispanoamericana. Ciencia americanista. Diccionario de americanismos 


\section{A modo de introducción}

Me es grato participar en la conmemoración del cuarenta y cinco aniversario de la fundación del Departamento de Lengua Española y Literaturas Hispánicas de la Cátedra de Estudios Ibéricos de la Facultad de Filología de la Universidad de Belgrado en Serbia.

Aprovecho esta oportunidad para rendir un merecido y profundo homenaje a la que fuera fundadora del Departamento y de la Cátedra, la distinguida hispanista serbia, catedrática doctora Ljiljana Pavlović-Samurović.

No cabe duda que el Departamento de Lengua Española y Literaturas Hispánicas en Serbia y en los Balcanes ha sentado las bases y continúa con más bríos, vehemencia y sapiencia a un mayor y mejor conocimiento, acercamiento y vinculación del acervo cultural de los pueblos de Hispanoamérica y la Península Ibérica con Serbia y viceversa.

Es imprescindible abordar aunque de manera somera, la recepción y trascendencia de la cultura latinoamericana y en particular de la cultura hispanoamericana en esta región de los Balcanes en los siglos XX y XXI.

A pesar de las grandes distancias geográficas, de las diferencias étnicas, lingüísticas y de cultura y civilización que existen entre Latinoamérica, en este caso Hispanoamérica y Serbia, ya podemos vislumbrar el comienzo de los lazos culturales con la llegada de los primeros inmigrantes yugoslavos a suelo latinoamericano a mediados del siglo XIX o posiblemente antes. Estos inmigrantes empezaron a establecerse en ciudades de América Latina a donde llevaron su cultura y absorbieron la de estas naciones, fusionándose biológica y culturalmente, dando como resultado los logros que han marcado, en algunos aspectos, el desarrollo de América Latina. (Mišović 1995)

\section{La recepción de la cultura hispanoamericana en Serbia}

En el siglo XX, más exactamente después de la primera Guerra Mundial, se va despertando el interés del pueblo yugoslavo ${ }^{2}$ hacia la cultura 
de los pueblos de América Latina que se presentará de manera esporádica hasta el año de 1969 para ir acrecentándose en las últimas décadas del siglo pasado y continuar en este nuevo milenio.

Ya a partir de los años setenta del siglo XX se reflejará de modo más patente y sobre todo en los últimos decenios y en este presente siglo, un mayor auge de la presencia cultural de América Latina y más que todo de Hispanoamérica en Serbia. (Izquierdo Todorović 1998)

Este interés es más perceptible y podríamos decir intenso en el campo de las traducciones de obras de autores hispanoamericanos y brasileños (novelas, cuentos, ensayos, etc. publicadas por casas editoriales $^{3}$ de la ex -Yugoslavia y de Serbia de gran prestigio y traducidas en su mayor parte por hispanistas de la antigua Yugoslavia, muchos de ellos formados en el Departamento de Lengua Española y Literaturas Hispánicas de la Facultad de Filología de la Universidad de Belgrado, Serbia.

Del mismo modo, aparecen traducciones de poesía hispanoamericana publicadas en antologías, revistas y periódicos especializados en literatura; presentación de recitales y muchas manifestaciones más de carácter cultural e informativo.

En este trabajo es importante mencionar la inclinación hacia el legado cultural de los pueblos precolombinos mediante traducciones de mitos, leyendas, cuentos y poesía; ponencias sobre estas culturas autóctonas; una traducción de algunos fragmentos de los "Comentarios reales" del Inca Garcilaso de la Vega, cronista mestizo y peruano del siglo XVI; tres traducciones del español: Popol Vuh el libro sagrado de los mayas y que recoge la historia y mitos del pueblo maya-Quiché, Rabinal Achí y ApuOllantay dramas de los pueblos maya e inca; obras del gran conocedor de la cultura azteca y renombrado profesor Miguel León- Portilla; un doctorado sobre estudios mesoamericanos otorgado por la Universidad Nacio-

mariscal Josip Broz Tito. Después vendrá la desintegración del estado ocurrida en 1992. A partir de entonces las antiguas naciones yugoslavas: Eslovenia, Croacia, Montenegro, Macedonia y Serbia se fueron independizándose hasta formar naciones independientes.

3 Prosveta, Nolit, Rad, Beogradski izdavački- grafički zavod, Književne novine, Savremena administracija, Paidea, Laguna, Clio, y otras de Belgrado, Serbia. Matica Srpska de Novi Sad. Bagdala de Kruševac. 
nal Autónoma de México (UNAM) y concedida a Sanja Savkić, hispanista serbia, egresada del Departamento; estudios de carácter literario, mesas redondas sobre la vida y obra de escritores hispanoamericanos contemporáneos; traducciones de obras de escritores hispanoamericanos contemporáneos; ponencias sobre literatura y cultura hispanoamericanas; obras teatrales; exposiciones de arte; películas; transparencias; vídeos; conciertos musicales; tesis doctorales; tesinas de pos-grado con temas referentes a la literatura hispanoamericana; tratados sobre literatura hispanoamericana; asignaturas sobre historia de la literatura hispanoamericana y de la cultura y un Diccionario de literatura hispanoamericana ${ }^{4}$.

A partir de 1930 en que aflora en Serbia la primera traducción de una obra hispanoamericana del escritor peruano Ventura García Calderón ${ }^{5}$ en este suelo balcánico, hacen también su aparición traducciones de obras de muchos escritores hispanoamericanos y una antología de poesía.

La traducción de la obra de Ventura García Calderón aparece en Serbia bajo el título Na međi, por B. Kalmić, seudónimo de Kalmi Baruh, hispanista yugoslavo, nacido en Sarajevo y publicada en "Narodna Knjižica", $\mathrm{n}^{\circ} 32$ de Belgrado, el año de 1930 y que contiene otros cuentos: Rađanje šuma ("La selva que Ilora"), Borba petlova ("Corrida de gallos"), Igla ("El alfiler"), Ljudožderske Priče ("Historia de caníbales"), Osveta kondora ("La venganza del cóndor"). Dos años más tarde, en 1932 del original Danger de Mort, Jovan Popovic hace la traducción al serbio como Plač prašume ("La selva que llora") publicada por la editorial Nolit de Belgrado, con comentarios de Milan Burlak (pp.7-13) y Claude Ferrere (pp.15-19) sobre el autor. De acuerdo a los estudios de la hispanista serbia Pavlović-Samurović, la traducción del cuento Plač prasume, surge más temprano, en 1929 como Plač prašume con una crítica de Milan Burlak y publicada por "Nova literatura", revista de la editorial Nolit de Belgrado. (Pavlović-Samurović 1983: 123)

Según Srpska bibliografija knjiga: 1868-1944 (Bibliografía de libros serbios: 1868-1944), esta edición se considera como la única traducción

4 Pavlović-Samurović, Ljiljana. Leksikon hispanoameričke književnosti. Beograd: Savremena administracija, 1993

5 Ventura García Calderón. Escritor peruano (1885-1959) Poeta, narrador modernista. Entre sus cuentos destacan la Venganza del cóndor, Peligro de muerte. Contribuyó a la difusión de la literatura hispanoamericana. 
autorizada de la colección de narraciones de Ventura García Calderón en idioma serbio.

En un aparte especial, es necesario mencionar que el año de 1996, sale a luz la reedición del cuento de V. García Calderón, La selva que llora, en traducción de Jovan Popović del año 1932. Editada por Babun de Belgrado y bajo los auspicios de la Embajada peruana en Serbia.

El año de 1970 como hemos nombrado anteriormente, significa también, la inclinación sistemática hacia las traducciones de obras de escritores hispanoamericanos y brasileños ${ }^{6}$ Entre los escritores hispanoamericanos traducidos al serbio, podemos nombrar a Jorge Icaza, Rómulo Gallegos, Miguel Ángel Asturias (premio Nobel de literatura, 1967), Gabriela Mistral (premio Nobel de literatura, 1945), Pablo Neruda (Premio Nobel de literatura,1971), José Hernández, Juan Liscano, Mario Monteforte Toledo, Horacio Quiroga, Carlos Fuentes, Alcides Arguedas, Alejo Carpentier, Jorge Luis Borges, Gabriel García Márquez (premio Nobel de literatura, 1982), Mario Vargas Llosa (premio Nobel de literatura, 2010), Juan Rulfo, Manuel Scorza, Julio Cortázar y otros.

Por consiguiente las obras de Gabriel García Márquez, Mario Vargas Llosa, Julio Cortázar, Isabel Allende, Paulo Coelho, sobrepasan tiradas de miles de ejemplares. Se ha podido comprobar que las obras de tres escritores, el colombiano Gabriel García Márquez, los peruanos Manuel Scorza y Mario Vargas Llosa, están traducidas a los idiomas serbio, croata, esloveno y albanés de Kosovo y con excepción de Scorza, han alcanzados un sinnúmero de ediciones.

El ensayo Simon Bolivar Oslobodilac ("Simón Bolívar, el Libertador") escrito en 1930 por el insigne escritor yugoslavo Ivo Andrićㄱ (premio

6 José de Alencar (1829-1877), novelista; Joaquín María Machado de Assis (18391909), novelista y poeta; Jorge Amado (1912-2001), novelista y narrador; Paulo Coelho (1947- ) , novelista.

$7 \quad$ Sobre las obras editadas y traducidas del escritor yugoslavo Ivo Andric ( 1892-1975) se pueden consultar: Srpska akademija nauka i umetnosti (Academia de Artes y Ciencias de Serbia); Biblioteka Ivo Andrić- bibliografija, dela. Prevod, literatura (Biblioteca Ivo Andrić- bibliografía, obras, traducciones, estudios críticos) Belgrado, 1974 Jugoslovenska književnost u inostranstvo (Literatura yugoslava en el extranjero) Bibliografías VII, XVI, XX, XXII de los años 1965, 1975, 1976, 1979, 1982, Belgrado. Zadužbina Ivo Andrić (Fundación de Ivo Andrić) Biografía completa de las obras editadas y traducidas, Belgrado 
Nobel de Literatura, 1961) fue editado en Srpski književni glasnik, "Gaceta Literaria de Serbia" el 1 y 16 de septiembre del mismo año. El año de 1982 el ensayo sale a luz en Caracas (Venezuela) a raíz del bicentenario del nacimiento del gran Libertador de América, con un texto introductorio y traducción al castellano de Salvador Prasel de origen yugoslavo, bajo el título Simón Bolívar, la libertad permanente, acompañado de un prólogo de José Luis Salcedo-Bastardo, Presidente del Comité Ejecutivo del Bicentenario de Simón Bolívar y publicado por el mismo Comité.

En 1983, en traducción bilingüe (español-serbio y serbio-español) auspiciada por la Embajada de Venezuela en Belgrado, se presenta al público belgradense la misma traducción de S. Prasel, Simón Bolívar, la libertad permanente con prólogo de J.L.Salcedo-Bastardo. Este volúmen va acompañado de un artículo de Andric como síntesis de su ensayo: Simon Bolivar Oslobodilac, publicado en el diario Politika el 21 de diciembre de 1930. El libro además del ensayo de I. Andrić lleva consigo un poema Un canto para Bolívar ("Pesmu Bolivaru") de Pablo Neruda, poeta chileno, traducido al serbio por N. Milićević; El Libertador ("Oslobodilac") de Miguel Otero Silva ( poeta y novelista venezolano) en versión de R. Ostojic y los trabajos elaborados por conocedores serbios sobre el tema, publicados por la casa editorial Bagdala de Kruševac (Milovanović, M. 1980; Ilić, Z. 1980) y en traducción bilingüe de Radica Ostojić, hispanista serbia, egresada del Departamento.

El mismo año, la misma editorial publica otro libro que recoge documentos escritos por Bolívar, en traducción bilingüe bajo el nombre "Misao Simona Bolivara - Pensamiento de Simón Bolívar".

También existen hasta la fecha otros estudios de carácter multidisciplinar del mismo ensayo (Pavlović-Samurović, Lj. 1992; Pajović, S. y Radovich, C. 2007; Izquierdo Todorović, S. 2012), como también otros estudios de cuestiones y autores hispanoamericanos presentados en congresos internacionales (Pavlović-Samurović Lj. 1996)

Es significativo nombrar el paralelo que encuentra y formula Zagorka Lilić (Lilić, Z 1995), entre Vuk Stefanović Karadžić (1787-1864), lingüista, etnólogo e historiador serbio y Andrés Bello (1781-1865), filólogo, filósofo y literato venezolano. El primero reformador del idioma serbio, conocedor de las costumbres de su pueblo y que escribió entre otras obras Prvi 
srpski BUKVAR ("El primer abecedario serbio·), editado en Viena en 1827 y el segundo con su obra maestra Gramática destinada al uso de los americanos en 1847, ambos contemporáneos, que luchaban al mismo tiempo y en dos puntos tan distantes del hemisferio, por la creación de una cultura nacional.

En los últimos decenios del siglo XX y en este presente siglo, el interés se ha multiplicado hacia las obras de Gabriel García Márquez, Mario Vargas Llosa (ambos autores tienen casi todas sus obras traducidas al serbio), Jorge Luis Borges, Carlos Fuentes, Nicolás Guillen, Miguel Otero Silva, Octavio Paz, Alejo Carpentier, Julio Cortázar, Isabel Allende, una obra de Sor Juana Inés de la Cruz (poetisa mexicana del siglo XVI), una de Tomás Eloy Martínez, un ensayo de carácter filosófico de Horacio Cerutti Guldberg, una novela de Luis Sepúlveda y una obra de poesía de Francisco Azuela.

Hay que poner en evidencia, la labor de difusión cultural e informativa que vienen realizando el Colegio Filológico de Belgrado, la Asociación Yugoslava de Latinoamericanistas ${ }^{8}$, el Instituto Cervantes, la Asociación de Hispanistas y algunas instituciones relevantes que por ahora de manera limitada divulgan la cultura de los pueblos de América Latina tales como las Embajadas de Latinoamérica en el país, la Fundación Ilija M. Kolarac, el Palacio de la Princesa Ljubica, el Museo Etnológico, la Biblioteca Nacional, el Centro Cultural Estudiantil, la cinemateca, teatros, radio y televisión y otras instituciones. En su momento tuvo mucha actividad el Centro de Estudios de España e Iberoamérica (CEEI) del Instituto de Política y Economía Internacional.

Una contribución significativa en Serbia y en los Balcanes y de gran valor sobre los estudios latinoamericanos, aporta el Departamento

8 Asociación Yugoslava de Latinoamericanistas - Jugoslovensko udrženje latinoamerikanista. Fundada en 1988, con sede en Belgrado. Entre otras actividades culturales cuenta con la publicación de tres libros: Latinska Amerika i savremeni svet - América Latina y el Mundo Contemporáneo. Eds. Jugoslovensko udruženje latinoamerikanista i Institut za međunarodnu politiku i privredu. Belgrado, 1995; Latinska Amerika u XX veku - América Latina en el siglo XX. Ed. Jugoslovensko udruženje latinoamerikanista. Belgrado,1999; Brazil-Pet vekova postojanje (1500-2000)-Brasil-Cinco siglos de existencia (1500-2000). Eds. Jugoslovensko udruženja latinoamerikansta i Idea. Belgrado, 2000. 
de Estudios de América Latina y el Caribe (DEALC) ${ }^{9}$ de la Facultad de Economía Internacional de la Universidad John Naisbitt (ex - Universidad Megatrend). Este Departamento fundado en 2001, desde un enfoque interdisciplinar y multidisciplinar, engloba estudios comparativos en los campos de economía, política y cultura de América Latina y el Caribe con Serbia y los Balcanes. Dicho Departamento está vinculado a instituciones internacionales como CEISAL, CESLA, EuPRA, FIEALC y otras, cuyos temas son referentes a todas las áreas de América Latina.

Debemos destacar indudablemente la labor educativa y cultural del Departamento de Lengua Española y Literatura Hispánicas de la Facultad de Filología y Arte de la Universidad de Kragujevac, Serbia, en menor medida el Departamento de Estudios Romances de la Universidad de Novi Sad, Vojvodina, Serbia y el Instituto de Literatura y Arte de Serbia.

El aspecto socio-político, económico y cultural de América Latina y de América Hispana en esta parte de los Balcanes es tema continuo de estudios y cuenta con instituciones y expertos en esta problemática como son (Grečić,V., Levi R., Paligorić Lj., Pajović.S,S., Redžepagić,S. 1995), (Pajović S.S., Andrijević M. 2010)

\section{Los estudios de la cultura hispanoamericana en el Departamento de Lengua Española y Literaturas Hispánicas. Desde una perspectiva personal}

No obstante, sin duda alguna, el lugar privilegiado y de gran envergadura en el estudio sistemático, tanto desde el punto de vista comparativo, multidisciplinar e interdisciplinar de la lengua española y la cultura española e hispanoamericana, ocupa en Serbia y en los Balcanes el Departamento de Lengua Española y Literatura Hispánicas de la Cátedra de Estudios Ibéricos de la Facultad de Filología de la Universidad de Belgrado en Serbia.

Fundada en 1971, anteriormente desde el año de 1962, se impartía el idioma español sólo como materia optativa. En sus inicios tenía el nombre de Departamento de Lengua y Literatura Española, pero luego

9 El Departamento de Estudios de América Latina y el Caribe está bajo la dirección del profesor doctor Slobodan S. Pajović, experto en América Latina. Hispanista serbio, egresado del Departamento de Lengua Española y Literaturas Hispánicas. 
después, exactamente, en el año 2000 del pasado siglo, ya creada la Cátedra de Estudios Ibéricos, lleva el nombre de Departamento de Lengua Española y Literaturas Hispánicas.

Desde su fundación el Departamento y la Cátedra estuvieron a cargo de la catedrática doctora Ljiljana Pavlović-Samurović, hasta su fallecimiento acaecido el año 2006. El Departamento cuenta ahora con la colaboración de profesores competentes, la mayoría de ellos egresados de este Centro de Estudios. Muchos de estos profesores continuaron su perfeccionamiento profesional en universidades de España, Francia, México, Perú y Estados Unidos.

En este Claustro de Estudios no sólo se imparte la enseñanza de la lengua, literatura y cultura españolas, sino también, desde algunos decenios, se dicta la asignatura de Historia de la Literatura Hispanoamericana a cargo de hispanistas serbios, la profesora doctora Ljiljana PavlovićSamurović, el profesor doctor Dalibor Soldatić y la doctora Vesna Dickov. También se dicta un curso complementario de Introducción a la Cultura y Civilización Hispanoamericana (Pavlović - Samurović 1992)

El objetivo del curso complementario es incentivar a los estudiantes de manera sistemática y estructural al estudio de la cultura y la civilización hispanoamericanas y despertar en ellos el interés hacia el estudio de un tema tan complejo como es la cultura de América Hispana. La estructura del curso está concebida de tal manera que empieza con el conocimiento de la realidad geográfica de Hispanoamérica inseparable de su historia para continuar con la diversidad de pueblos, idiomas que se hablan, religiones que se profesan, teorías sobre la llegada del hombre a la América, continuando con el nacimiento y desarrollo de las culturas precolombinas, nacidas en las áreas mesoamericanas y andinas; las grandes civilizaciones maya, azteca e inca; fuentes de investigación sobre estas culturas y civilizaciones que se desarrollaron en su territorio (Izquierdo Todorović 2005) Estas culturas se abordan minuciosamente a partir de su ubicación geográfica, orígenes, pasando por su desarrollo político, económico, social, científico, artístico, literario, religioso, ideográfico, idiomático y cultural y el legado que dejaron al mundo contemporáneo. Se da un merecido análisis a las literaturas de estos pueblos ancestrales que se consideran, según algunos estudiosos de esta problemática como el comienzo de la literatura en América Hispana. 
Se hace un seguimiento por los descubrimientos, conquistas y la formación y el desarrollo cultural de las colonias españolas; la creación de nuevas instituciones de carácter socio-político, económico y cultural creadas tanto en la Península como en América. Se continúa con las luchas por la liberación y la independencia de las colonias, abordando también el papel primordial de algunos héroes que se destacaron por sus ideas e ideales en estas luchas; la formación de los estados actuales o repúblicas y terminando con el análisis del aspecto geográfico, político, social, económico y cultural de cada país. Al final de cada capítulo tratado son de gran importancia las Notas que nos aclaran diversos términos, palabras amerindias, pueblos autóctonos, americanismos, etc. de los temas elaborados.

Se ha considerado de suma importancia hacer hincapié en las biografías y obras de ilustres pensadores y el alcance intelectual y visión cultural muy significativos para el futuro de la identidad hispanoamericana.

También se hace énfasis en el estudio de la ciencia americanista y los americanismos que surgen a través de los temas realizados, como son los americanismos provenientes de lenguas amerindias, de lenguas africanas, del patrimonio nacional, arcaísmos traídos de España y que han perdurado en el habla de Hispanoamérica, de la misma manera que palabras incorporadas de otros idiomas. No se ha dejado a un lado las diferencias que existen en los americanismos entre un país y otro, que hoy en día forman parte de la riqueza de la lengua, literatura, costumbres, folklore de los pueblos de América Hispana.

Hay que poner en evidencia que ya desde los primeros años de la enseñanza, se presenta a los jóvenes estudiantes una visión generalizada de la cultura hispanoamericana, englobando geografía, historia, lengua, literatura y costumbres para ir profundizándola en los últimos años de estudio.

Sin embargo, debemos recalcar, que el inicio del estudio de la cultura y la civilización hispanoamericana en el Departamento de Lengua y Literaturas hispánicas en el año 1971, fue hasta cierto punto espontáneo, natural. En los primeros años se utilizaba un manual escueto sobre cultura hispanoamericana que se editaba en la Facultad de Filología y que con el correr de los años se convertiría en un libro de texto que recoge en sí de forma estructurada y metodológica no sólo la cultura y civilización 
hispanoamericana, sino también, latinoamericana; siempre teniendo en cuenta que la enseñanza y aprendizaje de una lengua, más que todo, si se trata del aprendizaje de una lengua, en este caso, el español o castellano como idioma extranjero, no puede ni debe ir desligada de su cultura, de su historia, en suma, de su civilización, para transformarse con el tiempo en una materia de estudios complementarios de mayor alcance en lo que se refiere tanto a la enseñanza como a la difusión del acervo cultural de los pueblos hispanoamericanos.

\section{Consideraciones finales}

Podemos concluir este trabajo, afirmando que la cultura hispanoamericana como materia de estudios en el Departamento de Lengua Española y Literaturas Hispánicas de la Cátedra de Estudios Ibéricos de la Facultad de Filología de la Universidad de Belgrado de Serbia ha logrado un lugar privilegiado en el mundo académico y en otros círculos culturales en Serbia y en el resto de los Balcanes.

En este Departamento, la cultura hispanoamericana está tratada desde un punto de vista científico, estructurado, metodológico, comparativo, donde creemos que ha conseguido ser un modelo de referencia y orientación científica para los jóvenes hispanistas y otras instituciones que en el futuro se sientan atraídos hacia la diversidad de áreas que ofrece Hispanoamérica. También, nuestra intención ha sido, en el transcurso de la formación académica de los futuros hispanistas, dejar muy en claro tres momentos claves en la consolidación de la identidad hispanoamericana:

1. En primer lugar, el estudio de la cultura hispanoamericana en el Departamento ha asentado los conocimientos con respecto a que en suelo americano, surgieron grandes culturas y civilizaciones que alcanzaron un desarrollo socio-político, económico, literario y cultural impresionantes. Estas culturas perduran en nuestros días y por muy lejanas que parezcan, su pervivencia y proyección es perceptible ya como sincretismo cultural, ya como materia de estudios científicos realizados y por realizar. 
2. En segundo lugar ha conseguido reafirmar el enfoque hacia el entendimiento de la transculturación, fenómeno biológico-cultural, o sea la fusión de la cultura española y las culturas oriundas o vernáculas del continente americano. Todos estos pueblos se mezclaron a partir del siglo XV continuado en los siglos XVI, XVII y XVIII, dando como resultado un mestizaje en todas sus formas $y$ variedades. Un mestizaje que se ha visto enriquecido con el correr de los siglos por la llegada de nuevas inmigraciones de pueblos de todas partes del mundo al continente americano, y por ende, una sociedad multiétnica o crisol de culturas.

3. Y por último el estudio de la cultura hispanoamericana en el Departamento ha dado a conocer el nacimiento de una intelectualidad e identidad hispanoamericana propias que reúnen en sí una unidad plural y al mismo tiempo, diferenciada, fruto de este mestizaje o sincretismo de razas y de culturas.

Sin embargo, creemos necesario sugerir, que a pesar de estos logros alcanzados en el Departamento de Lengua Española y Literaturas Hispánicas en el campo de la cultura hispanoamericana, habría que dar cabida a los estudios de la ciencia americanista que nos da a conocer el aspecto físico, el modo de vida, costumbres, lenguas, historia de los pueblos amerindios, antes y después de la llegada de los europeos. Estos temas están tratados por expertos a nivel mundial. Existen en nuestros días una gran producción de libros, monografías, publicaciones, instituciones tanto en América como en el resto del mundo que aportan de manera crítica una visión, cada vez más completa de la historia y cultura de los pueblos de América. También debería recibir un lugar merecido el estudio y explicación concienciada de los americanismos de estos pueblos, que a la par que les diferencian, les unen aún más, no sólo entre sí, sino también con España.

Finalizando este trabajo sería necesario plasmar los americanismos provenientes de lenguas amerindias, del patrimonio nacional, de arcaísmos traídos de España y palabras llegadas de otras latitudes, en un Diccionario de americanismos. 


\section{BIBLIOGRAFÍA}

Grečić, Vladimir. „Odliv mozgove iz Latinska Amerika, uticaj na razvoj pojedinih zemalja“. Latinska Amerika i savremeni svet. Beograd: Eds. Jugoslovensko udruženje latinoamerikanista i Institut za međunarodnu politiku i privredu, 1995. 304-310. Štampano.

Izquierdo-Todorović, Silvia. „Pre-inkaičke kulture“. Latinska Amerika i savremeni svet. Beograd: Eds. Jugoslovensko udruženje latinoamerikanista i Institut za međunarodnu politiku i privredu, 1995. 111-118. Štampano.

Izquierdo-Todorović, Silvia. "La recepción de la cultura latinoamericana en Yugoslavia: caso de estudio la Facultad de Filología de la Universidad de Belgrado". Prioridades en las relaciones entre RF de Yugoslavia (Los Balcanes), España y América Latina. Belgrado: Ed. Centro de Estudios de España e Iberoamérica (CEEI) del Instituto de Política y Economía Internacional, 1998. 55-64. Impreso.

Izquierdo-Todorović, Silvia. Introducción a la Civilización Latinoamericana Uvod u latinoameričku civilizaciju. Belgrado: Ed. Megatrend univerzitet, 2005. Impreso.

Izquierdo-Todorović, Silvia. "La recepción de la figura de Simón Bolívar y su obra en Serbia". Europa Central y los países de la Cuenca del Mar Negro-MERCOSUR: dinámicas e interacción. Belgrado: Eds. CEISAL y Universidad Megatrend, 2012. 291-303. Impreso.

Levi, Rozita. „Panamerikanizam - od ideje do realizacije“. Latinska Amerika i savremeni svet. Beograd: Eds. Jugoslovensko udruženja latinoamerikanista i Institut za međunarodnu politiku i privredu, 1995. 209-225. Štampano.

Lilić, Zagorka. „Andrićevo oduševljenje Bolivaru - La Fascinación de Andrić por Simón Bolívar". Bolivar neprekidna sloboda-Bolívar la libertad permanente. Kruševac: Ed. Bagdala, 1983. 87-91. Štampano.

Lilić, Zagorka. „Veze na kulturnom, posebnom literarnom planu, kao spona izmedju Latinska Amerika i nasih naroda." Latinska Amerika i savremeni svet. Beograd: Eds. Jugoslovensko udruženje latinoamerikanista i Institut za međunarodnu politiku i privredu, 1995. 145-151 Štampano.

Milovanović, Milena. „Ivo Andrić u Svetu - Ivo Andrić en el Mundo“. Bolivar neprekidna sloboda-Simón Bolívar la libertad permanente. Kruševac: Ed. Bagdala, 1983. 75-83. Štampano.

Pajović, Slobodan. "Novi oblici političke saradnje u Latinskoj Americi“. Latinska Amerika i savremeni svet. Beograd: Eds. Jugoslovensko 
udruženje latinomerikanista i Institut za međunarodnu politiku i privredu, 1995. 226-238. Štampano.

Pajović, Slobodan y Radovich Carlos. "Simón Bolívar en la obra de Ivo Andrić". Europa Balcánica y los países de la cuenca del Mar Negro-MERCOSUR: Procesos de transición, cooperación económica, política y cultural. Belgrado: Eds. CEISAL y Universidad Megatrend, 2007. 321-338. Impreso.

Pajović, Slobodan, y Maja Andrijević. "Los estudios latinoamericanistas en Serbia". Anuario latinoamericanista europeo. No. 8 (2010): 192207. Impreso.

Paligorić, Ljubomir. „Četiri teze o latinoameričkoj istoriji“. Latinska Amerika i savremi svet. Beograd: Eds. Jugoslovensko udruženje latinoamerikanista i Institut za međunarodnu politiku i privredu, 1995. 69-79. Štampano.

Pavlović-Samurović, Ljiljana. „Moderna književnost na španskom jeziku u Nolitovim predratnim izdanjima“. Anali Filološkog fakulteta. Knj. XV (1983): 121-128. Štampano.

Pavlović-Samurović, Ljiljana. „Andrić o Simonu Bolivaru“. Ivo Andrić u svome vremenu. Zbornik radova sa XXII Međunarodnog naučnog sastanka slavista u Vukove dane u Beogradu, Novom Sadu i Tršiću. (15-20.9.1992). Beograd: MSC, 1992. 305-315. Štampano.

Pavlović-Samurović, Ljiljana. "Los estudios hispánicos en Serbia". Estudios Latinoamericanos e Ibéricos en la Europa Centro-Oriental, Nórdica y Balcánica. Varsovia: Ed. CESLA, 1992. 45-46. Impreso.

Pavlović-Samurović, Ljiljana. Leksikon hispanoameričke književnosti. Beograd: Ed. Savremena Administracija, 1993. Štampano.

Pavlović-Samurović, Ljiljana. "Una tentativa de interpretación sobre la herencia nacional en la poesía hispanoamericana y en la poesía serbia moderna". América Latina e Europa Central-Oriental: perspectivas para o Terceiro Milenio. Río de Janeiro: Ed. CESLA, 1996. 59-70. Impresso.

Redžepagić, Sulejman. „Paradoksi i dileme Latinske Amerike“. Latinska Amerika i savremi svet. Beograd: Eds. Jugoslovensko udruženje latinoamerikanista i Institut za međunarodnu politiku i privredu, 1995. 186-200. Štampano.

Srpska bibliografija knjiga: 1868-1944. Knj. 4. Beograd: Narodna biblioteka Srbije, 1922. Štampano. 


\title{
Silvia Izquierdo-Todorović
}

\section{HISPANIC AMERICAN CULTURE AT THE DEPARTMENT OF SPANISH LANGUAGE AND HISPANIC LITERATURES. A PERSONAL PERSPECTIVE}

\begin{abstract}
Summary
The purpose of the present paper is to underline the importance and the central role of the Department of Spanish Language and Hispanic Literatures in the study of Hispanic American culture, not only in Serbia, but also in the Balkans. Our aim is to present the reception of Hispanic American culture in Serbia, with a special focus on the area of translation from Spanish into Serbian and vice versa, in which the graduate students of this Department are very involved. Hispanic American culture has been studied at this Department since its foundation, along with studies of Spanish language, literature and culture. It has been approached from a scientific, structured, methodological and multidisciplinary point of view, starting with ancient cultures and civilizations and their persistence over time, whose projection is perceptible as a cultural syncretism and represents a frequent topic of different scientific researches. We will also analyze the phenomenon of transculturation, which is of great importance to becoming acquainted with and understanding the Hispanic American identity. Transculturation, or biological and cultural fusion, of Spanish people and major vernacular cultures has led to miscegenation, which has had a great impact in all areas of Hispanic American culture, further enriched with new immigrations resulting in the constitution of multi-ethnic and multicultural societies. We propose the introduction of a new discipline - Hispanic American studies (ciencia americanista) - and the elaboration of a Latin-American Spanish dictionary (diccionario de americanismos).

Keywords: Department of Spanish Language and Hispanic Literatures, Hispanic American culture, syncretism of cultures, miscegenation, Hispanic American identity, Hispanic American studies (ciencia americanista), Latin-American Spanish dictionary (diccionario de americanismos).
\end{abstract}

